\title{
Comparison of clinical aspects and Mantoux test in tuberculosis versus non-tuberculosis superficial lymphadenitis
}

\author{
Siti Nilawardhani, MD; Helmi Lubis, MD; Ridwan M Daulay, MD; Gabriel Panggabean, MD; \\ Siti Mirhalina Hasibuan, MD
}

\begin{abstract}
Objective To investigate the clinical aspects and result of Mantoux test in superficial lymphadenitis caused by Mycobacterium tuberculosis (MTB) compared to that caused by non-MTB organisms.

Methods This was a cross sectional study conducted on 86 patients aged between 3 months and 14 year-old with enlargement of the superficial lymph nodes, 43 with tuberculosis superficial lymphadenitis (TSL) and 43 with non-tuberculosis superficial lymphadenitis (NTSL). The diagnoses of TSL and NTSL were confirmed by histopathological examination. Clinical symptoms and Mantoux test were examined in this study.

Results In the TSL group, most children (70\%) were in the age of $>5-14$ year-old, while in the NTSL, most (46\%) were $1-5$ years old. The most frequent chief complaint in the TSL group was fever $(37 \%)$, while in the NTSL group, cough $(49 \%)(p=0.004)$. Failure to thrive and loss of appetite were more frequently found in the TSL ( $70 \%$ and $35 \%$ ) compared to the NTSL group ( 0 and $3 \%)(p=0.004)$. Most enlarged nodes in TSL were multiple $(67 \%)$, while in NTSL, solitary $(72 \%)(p<0.001)$. There were no differences in the location and distribution of enlarged nodes between the two groups. Thirtyone $(72 \%)$ children in the TSL group had positive Mantoux test, while in the NTSL group were only $2(5 \%)(p<0.001)$.

Conclusions Most children with TSL had fever as the chief complaint while those with NTSL had cough. Children with TSL had failure to thrive, loss of appetite, multiple nodes, and positive Mantoux test more frequently compared to NTSL ones [Paediatr Indones 2004;44:55-60].
\end{abstract}

Keywords: Clinical aspect, Mantoux test, tuberculosis superficial lymphadenitis, fine needle aspirate.

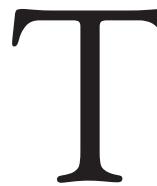

Uuberculosis (TB) of the superficial lymph nodes is the most common form of extra pulmonary tuberculosis in children, and it is the most common complication of primary tuberculosis. ${ }^{1-5}$ It occurs with a frequency of $30-64 \%,{ }^{2}$ dominantly in the female with a ratio of $2: 10^{1,4,5}$ Enlargement of the superficial lymph nodes is not only caused by Mycobacterium tuberculosis (MTB) but also by non Mycobacterium tuberculosis. Previous studies showed the importance of differentiating the two diseases by history taking of contact with tuberculosis patient, chest $\mathrm{x}$-ray, result of aspiration biopsy for cytology, and culture from the gland involved. 1,6-8 There are many opinions about this but they are still variable. For the management of tuberculosis superficial lymphadenitis (TSL), it is best to know the clinical aspects and the result of the Mantoux test. This is because there are many conditions that are similar to TSL. The clinical signs of tuberculosis (TB) are divided into general or systemic signs such as cough, fever, anorexia, weight loss, night sweating, and malaise ${ }^{9}$ and specific manifestation such as the enlargement of the superficial lymph nodes, which is not painful and can be bilateral or multiple. 1,2,7,9 Previous studies showed

From the Departments of Child Health (SN, HL, RMD, GP) and Pathology $(\mathrm{SMH})$, Medical School, University of Sumatera Utara, Medan, Indonesia.

Reprint requests to: Siti Nilawardhani, MD, Department of Child Health, Medical School, University of Sumatera Utara, Adam Malik Hospital, Medan, Indonesia. Tel/Fax. 62-61-8361721. 
a correlation between lymph node tuberculosis and the location, distribution and amount of the infected glands. ${ }^{10-12}$ Enlargement of the lymph nodes outside the cervical area indicates a serious form of TB with systemic process. ${ }^{7,13}$ Another opinion stated that multiple process is frequently found in the enlargement of superficial lymph nodes caused by MTB. ${ }^{7,11,14}$

The aim of this study was to investigate the clinical aspects and result of Mantoux test in superficial lymphadenitis caused by Mycobacterium tuberculosis compared to that caused by non-tuberculosis organism.

\section{Methods}

This was a cross sectional study conducted from May 2001 to May 2002 on children aged between 3 months and 14 years who came to the Pulmonology Outpatient Clinic (BP4 or Balai Pengobatan Penyakit Paru), Pirngadi Hospital, Medan, with enlargement of the superficial lymph nodes. Patients suffering from severe illness such as typhoid fever, whooping cough, or severe tuberculosis, viral diseases such as measles, mumps, rubella or small pox, malignancy, chronic renal failure, malnutrition, also those with corticosteroid medication for more than 2 weeks, were excluded from this study.

The number of samples needed was 43 for each group, the TSL and NTSL (non-tuberculosis superficial lymphadenitis) group. Samples were recruited by consecutive sampling. The diagnosis of TSL was confirmed by histopathological examination.

Every patient was interviewed concerning his main complaint and history of contact with tuberculosis patients and underwent clinical examination. Tuberculin skin test was performed using Mantoux method and after that the patient was referred to the Department of Pathology for an aspiration biopsy examination of the enlarged lymph node. Informed consent was obtained from every patient. The evaluation of the nutritional status was done using the WHO NCHS curve and classified according to the Semiloka Anthropometrics 1991. Severe malnutrition was defined if the body weight was below -3 standard deviation of the NCHS curve. We measure the dimensions of the lymph node using a ruler. We also noticed the location, total number, and tenderness of the nodes. Fine needle aspirate (FNA) examination was done at the Department of Pathology, Pirngadi Hospital. If the result of the FNA was a specific process, we classified it as TSL and if the result was a non-specific process we classified it as NTSL.

The tuberculin skin test using the Mantoux method was done during the patients' visit by an intradermal injection on the central volar area of the lower left arm, which was carried out by an experienced officer. The reagent used was PPD 5 TU (Bio Farma, Bandung) with the dosage of $0.1 \mathrm{ml}$. The result was evaluated 72 hours after injection. A positive Mantoux test was defined if the induration was $315 \mathrm{~mm}$ in a child who had already had Bacilli Calmette-Guerin (BCG) immunization. BCG immunization history was considered negative if there was neither data of immunization nor BCG scar.

Cough was considered a complaint if it lasted continuously for at least two weeks or occurred at least 3 times in three months. Failure to thrive was defined if the child's body weight did not increase in more than six months or the child became thinner. Loss of appetite was considered a complaint if it lasted for more than 2 weeks.

Statistical analysis were done by using the SPSS 10.0 computer program. Chi-square was used to compare the clinical aspects and Mantoux test of TSL to that of NTSL. A p value of $<0.05$ was considered statistically significant.

\section{Results}

During the study period there were 98 children with lymph node enlargement who sought medication to the BP4, Pirngadi Hospital. Twelve children did not meet the inclusion criteria and were excluded from this study.

The characteristics of the subjects are described in Table 1. Table 1 shows that the most frequent age in the TSL group was between 5 and 16 years and in the NTSL group was $1-5$ years. There were no differences in sex and nutritional status distribution in both groups.

Table 2 shows the clinical aspects of both groups. There was a statistically significant difference in the chief complaint between the two groups. In the TSL group, the most frequent symptom was fever which was found in 16 patients (37\%), while in the NTSL group, was cough. There were significant differences 
Siti Nilawardhani et al: Clinical aspects and Mantoux test in tuberculosis versus non-tuberculosis superficial lymphadenitis

Table 1. Characteristics of patients

\begin{tabular}{|c|c|c|c|c|}
\hline \multirow{3}{*}{ Characteristics } & \multicolumn{2}{|c|}{ Patients } & \multirow[b]{2}{*}{ Total } & \multirow[b]{2}{*}{$p$} \\
\hline & \multirow{2}{*}{$\begin{array}{l}\text { TSL } \\
\mathrm{n}(\%)\end{array}$} & \multirow{2}{*}{$\begin{array}{l}\text { NTSL } \\
\mathrm{n}(\%)\end{array}$} & & \\
\hline & & & n (\%) & \\
\hline Age & & & & $0.019^{*}$ \\
\hline$<1$ years old & $3 \quad(7)$ & $6 \quad(14)$ & $9 \quad(10)$ & \\
\hline $1-5$ years old & 10 (23) & $20(47)$ & $30(35)$ & \\
\hline$>5-14$ years old & 30 (70) & 17 (39) & $47(55)$ & \\
\hline Sex & & & & 0.261 \\
\hline Boy & $25(58)$ & $30(70)$ & $55(64)$ & \\
\hline Girl & $18(42)$ & $13(30)$ & $31(36)$ & \\
\hline Nutritional Status & & & & 0.747 \\
\hline Low & 10 (23) & $12(28)$ & $22(26)$ & \\
\hline Moderate & 12 (28) & $11(26)$ & $23(27)$ & \\
\hline Good & $20(47)$ & $20(46)$ & $40(46)$ & \\
\hline Over & $1 \quad(2)$ & $0 \quad(0)$ & 1 (1) & \\
\hline
\end{tabular}

Table 2. Comparison OF the CLINICAL CRITERIA IN TSL AND NTSL

\begin{tabular}{|c|c|c|c|c|c|c|}
\hline \multirow{3}{*}{ Clinical criteria } & \multicolumn{3}{|c|}{ Patients } & & \multirow{3}{*}{$\mathbf{p}$} \\
\hline & \multirow{2}{*}{\multicolumn{2}{|c|}{$\begin{array}{l}\text { TSL } \\
\text { n (\%) }\end{array}$}} & \multirow{2}{*}{$\begin{array}{l}\text { NTSL } \\
\text { n (\%) }\end{array}$} & & & \\
\hline & & & & \multicolumn{2}{|c|}{$\begin{array}{l}\text { Total } \\
\text { n (\%) }\end{array}$} & \\
\hline \multicolumn{6}{|l|}{ Chief complaint } & $0.004^{*}$ \\
\hline Cough & 12 & (28) & $21(49)$ & 33 & (38) & \\
\hline Fever & 16 & (37) & $4 \quad(9)$ & 20 & (23) & \\
\hline Enlarged Lymph node & 8 & (19) & $15(35)$ & 23 & (27) & \\
\hline Others & 7 & (16) & $3(7)$ & 10 & (12) & \\
\hline \multicolumn{6}{|l|}{ Complaint of failure to thrive } & $<0.001^{*}$ \\
\hline Yes & 30 & $(70)$ & $0 \quad(0)$ & 30 & (35) & \\
\hline No & 13 & (30) & $43(100)$ & 56 & (65) & \\
\hline \multicolumn{6}{|l|}{ Loss of appetite } & $0.004^{*}$ \\
\hline Yes & 15 & (35) & $4 \quad(9)$ & 19 & (22) & \\
\hline No & 28 & $(65)$ & $39(91)$ & 67 & (78) & \\
\hline \multicolumn{6}{|c|}{ Contact with Tuberculosis patient } & 0.812 \\
\hline Yes & 13 & (30) & $12(28)$ & 25 & (29) & \\
\hline No & 30 & $(70)$ & 31 (72) & 61 & (71) & \\
\hline
\end{tabular}

between the two groups in the complaint of failure to thrive and loss of appetite.

There was a statistically significant difference in the result of Mantoux test between the two groups (Table 3). Among 31 children in the TSL group with positive Mantoux test, there were 12 cases with BCG scar and 19 cases without BCG scar.

Enlargement of the lymph nodes was described in Table 4. It shows that most lymph node enlargements in the TSL group were multiple (29 cases or $67 \%$ ), while solitary node enlargement was found in only 14 cases $(33 \%)$. This was statistically different $(\mathrm{p}<0.05)$ with that of the NTSL group, in which only $12(28 \%)$ patients had multiple nodes. There were no significant differences in the location and distribution of the enlarged lymph nodes between the two groups.

\section{Discussion}

In this study, the most frequent age in the TSL group was between 5 and 14 years. This differs from Jha et $a^{2}$ study, in which most of the cases aged of 11-20 years, while Hooper ${ }^{27}$ reported that most of the cases occurred at the age of less than 12 years. This might be due to the difference in the age grouping between this study and that of the previous studies.

We found that there was no significant difference in sex distribution between the two groups. In the TSL group, there were 25 boys $(58 \%)$ while in the NTSL group there were 30 boys (70\%). Jha et al found more girls than boys in their study (1.3:1).

In this study, there was no significant difference in the nutritional status between both groups. Most 
Table 3. Comparison of Mantoux test in STL and SNTL

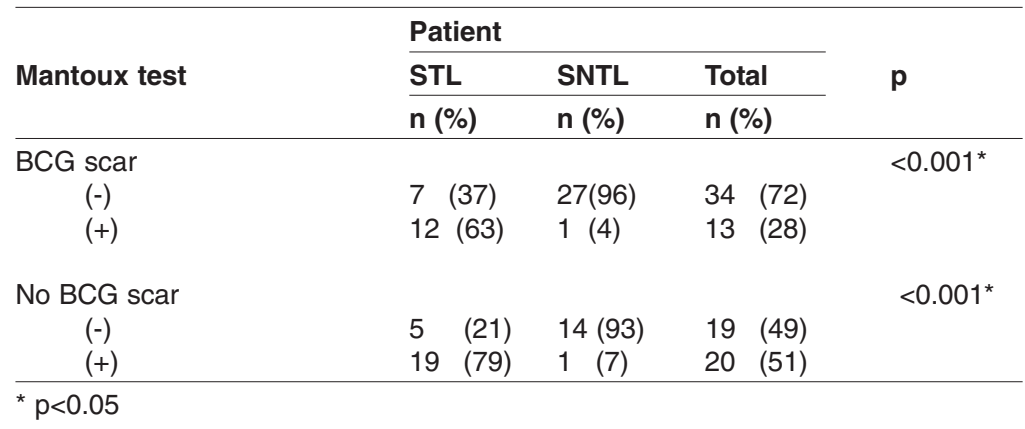

TABLE 4. ENLARGEMENT OF THE SUPERFICIAL LYMPH NODE IN TSL AND NTSL

\begin{tabular}{|c|c|c|c|c|c|c|}
\hline \multirow{2}{*}{$\begin{array}{l}\text { Enlargement of the } \\
\text { superficial lymph node }\end{array}$} & \multirow{2}{*}{\multicolumn{2}{|c|}{$\frac{\text { TSL }}{n(\%)}$}} & \multirow{2}{*}{\multicolumn{2}{|c|}{$\begin{array}{l}\text { NTSL } \\
\text { n (\%) }\end{array}$}} & \multirow{2}{*}{$\begin{array}{l}\text { Total } \\
\mathrm{n}(\%)\end{array}$} & \multirow[t]{2}{*}{ p } \\
\hline & & & & & & \\
\hline & & & & & & \\
\hline Neck & 19 & (44) & 26 & $(60)$ & $45(52)$ & \\
\hline Submandibula & 7 & (16) & 10 & (23) & $17(20)$ & \\
\hline Subclavicula & 5 & (12) & 2 & (5) & $7(8)$ & \\
\hline Inguinal & 1 & (2) & 2 & (5) & $3(4)$ & \\
\hline Axila & 5 & (12) & 2 & (5) & 7 (8) & \\
\hline Neck \& submandibula & 4 & (9) & 1 & (2) & $5(6)$ & \\
\hline General & 2 & (5) & 0 & (0) & $2(2)$ & \\
\hline \multicolumn{6}{|c|}{ Number of the enlarge lymph node } & $<0.001^{*}$ \\
\hline Solitary & 14 & (33) & 31 & (72) & $45 \quad(52)$ & \\
\hline Multiple & 29 & (67) & 12 & (28) & $41 \quad(48)$ & \\
\hline \multicolumn{6}{|l|}{ Distribution } & 0.084 \\
\hline Unilateral & 18 & (42) & 26 & (61) & $44 \quad(51)$ & \\
\hline Bilateral & 25 & (58) & 17 & (39) & $42 \quad(49)$ & \\
\hline
\end{tabular}

${ }^{*} p<0.05$

had good nutritional status, 20 out of 43 children in each group. Twelve children with under nutritional status were excluded from this study, because this could produce a false negative result on the Mantoux test.

There were significant differences in the chief complaint between both groups. In the TSL group, the most frequent symptom was fever [16 children (37\%)], only 8 children (19\%) complained of enlargement of the lymph nodes. The superficial lymph node enlargement caused by MTB usually grows slowly and does not cause any pain. This differs from previous studies in which most of the patients came due to enlargement of lymph nodes in the neck.7,16 The consensus in child TB stated that fever is one of the TB most common symptoms. ${ }^{6}, 17$ Palel and Mehta found fever in $40 \%$ of their patients. ${ }^{2}$ In our study, cough was the second most common chief complaint in the TSL group, which was found in 12 patients (28\%). The cough was recurrent and lasted for a long time. Ninety percent of patients with enlargement of superficial lymph nodes had lung involvement. ${ }^{4}$

Other prominent symptoms in the TSL group were failure to thrive, which occurred in $70 \%$ of patients. Parents usually complained a reduction of body weight. Dandapatan ${ }^{10}$ found reduction of body weight in $85 \%$ of patients, while Palel and Mehta found this symptom in $77 \% .^{2}$ We found $15 \%$ cases with anorexia. This could be caused by chronic illness and poor feeding pattern.

Manolidis ${ }^{13}$ found few symptoms of night sweating and malaise in tuberculosis lymphadenitis. In this study, there were $16 \%$ of children with night sweating and malaise in the TSL group.

Children usually suffer from this infection by contact with a source of infection which commonly is 
an adult with TB. Children with TB are said to have primary tuberculosis infection. ${ }^{1,18}$ We found no significant difference in the history of contact with adult TB between the two groups.

Tuberculin test using Mantoux method with PPD 5 TU plays an important role in establishing the diagnosis of TB. Fine needle aspiration (FNA) from enlarged superficial lymph nodes can minimize local complication compared to other techniques. ${ }^{19}$ Castro $^{14}$ found $100 \%$ positive tuberculin test in patients with superficial lymphadenitis caused by MTB. Geldmacher ${ }^{11}$ reported that $75 \%$ of TSL patients had positive tuberculin test. In our study, 31 (72\%) children in the TSL group had positive Mantoux test while only 2 children in the NTSL group got positive result.

We found no complaint of pain in the enlarged lymph nodes in both groups. The most common site of lymph node enlargement in order of occurrence is the neck (cervical), axilla, inguinal and submandibula. ${ }^{10,13,19}$ This finding did not differ from the previous study. We found that in both groups, lymph node enlargement mostly occurred in the neck (44\% and 60\% respectively) and submandibula (16\% and $23 \%$ respectively). Statistically, there was no significant difference between the two groups $(\mathrm{p}>0.05)$.

Most of the lymph node enlargements in the TSL group were bilateral which were found in 25 patients (58\%), while in the NTSL were only 17 patients (39\%). This was significantly different. Small ${ }^{4}$ found more patients with bilateral lymph node enlargement in children than in adults with TSL.

In our study, most of the lymph node enlargements in the TSL group were multiple [29 cases $(67 \%)$ ], while solitary enlargements were found only in 14 cases (33\%). Compared to the NTSL group, this was significantly different $(p<0.05)$. We found similar results with those from previous studies, which found that lymph node enlargement in TSL is usually multiple, 2,9,10,19 while those caused by Mycobacterium atypical was usually solitary, bilateral, and located at the corner of mandibula. ${ }^{8}$

All patients with specific FNA result and positive Mantoux test received 3 anti tuberculosis drug for at least 6 month with isoniazid, rifampicin and pyrazinamid in the first two months.

We concluded that the most frequent age of children with TSL and NTSL were different. Most chil- dren with TSL had fever as the chief complaint while those with NTSL had cough. Failure to thrive and loss of appetite were more common in TSL compared to NTSL. There was more multiple lymph node enlargement in TSL group compared to the NTSL group. Patients in the TSL group had more positive Mantoux test than those in NTSL group.

\section{References}

1. Grossman M. Tuberculosis. In: Rudolph AM, Hoffman JIE, Rudolph CD, editors. Rudolph's pediatrics. 20 th ed. New York: Prentice Hall Int; 1996. p. 614-23.

2. Jha BC, Dass A, Nagarkar NM, Gupta R, Singhal S. Cervical tuberculosis lymphadenophathy: changing clinical pattern and concepts in management. Postgard Med 2001;77:185-7.

3. Khan EA, Starke JR. Diagnosis of tuberculosis in children increased need better methods. Baylor College of Medicine 1997; 1:1-13.

4. Small PM, Selcer UM. Tuberculous adenitis. In: Strickland GT, editor. Tropical medicine and emerging infectious diseases. $8^{\text {th }}$ ed. Philadelphia: Saunders; 2001. p. 499.

5. Inselman LS, Kendig EL. Tuberculosis of the superficial lymph nodes. In: Chernick V, Kendig EL, editors. Disorders of the respiratory tract in children. $5^{\text {th }} \mathrm{ed}$. Philadelphia: Saunders; 1990. p. 759-60.

6. Loenhout-Rooyackers JH, Laheji RJF, Richter C, Verbeek ALM. Shortening the duration of treatment for cervical tuberculosis lymphadenitis. Eur Respir L 2000;15:192-5.

7. Starke JR. Tuberculosis. In: Behrman RE, Kliegman RM, Arvin AM, editors. Nelson textbook of pediatrics. $16^{\text {th }}$ ed. Philadelphia: Saunders; 1996. p. 34-47.

8. Cambell I, Drobniewski F, Novelli V, Ormerod P, Pozniak A. Management of opportunist mycobacterial infection: joint tuberculosis committee guideline 1999. Thorax 2000;55:210-8.

9. Rahajoe NN. Tatalaksana tuberkulosis pada anak. Sari pediatri 2001;3: 24-35.

10. Dandapat MC, Mishra BM, Dash SP, Kar PK. Peripheral lymph node tuberculosis: a review of 80 cases. $\mathrm{Br} \mathrm{J}$ Surg 1990;77:911-2.

11. Geldmacher H, Taube C, Kroeger C, Magnussen H, Kirsten DK. Assessment of lymph node tuberculosis in northern Germany. Chest 2002;121(4):1177-82. 


\section{Paediatrica Indonesiana}

12. Mignogna MD, Muzio LLO, Favia G. Oral tuberculosis: a clinical evaluation of 42 cases. Oral Disease 2000;6:25-30.

13. Manolidis S, Frenkiel S, Yoscovitch A, Black M. Mycobacterial infections of the head and neck. Otolaryngol head neck surg 1993;109:427-33.

14. Castro JJ, Hoover L, Castro DJ, Zuckerbraun L. Cervical mycobacterial lymphadenitis. Arch Otolaryngol 1985;111:816-9.

15. Hopewell PC, Bloom BR. Tuberculosis and other mycobacterial disease. In: Murray JF, Nadel JA, editors. Textbook of respiratory medicine. $3^{\text {rd }}$ ed. Philadelphia: Saunders; 1996. p. 34-47.
16. Gupta AK, Nayar M, Chandra M. Critical appraisal of fine needle aspiration cytology in tuberculosis lymphadenitis. Acta Cytologica 1992;36:391-4.

17. Rahajoe NN. Challenges of tuberculosis diagnosis and management in children. KONIKA XII; Bali, Indonesia.

18. Thompson MM, Underwood MJ, Sayers RD, Dookeran KA, Bell PRF. Peripheral tuberculosis lymphadenop-hathy: review of 67 cases. Br J Surg 1992;79:763-4.

19. Lau SK, Wei WI, Engzell UCG. Efficacy of fine needle aspiration cytology in the diagnosis of tuberculosis cervical lymphadenopathy. J Laryngo Otol 1990;104: 24-7. 